\title{
Electroejaculation: its technique, neurological implications and uses
}

\author{
G S B R I N D L E Y \\ From the Department of Physiology, Institute of Psychiatry, London
}

SUMMARY An improved technique for electroejaculation is described, with the results of applying it to 84 men with spinal injuries and five men with ejaculatory failure from other causes. Semen was obtained from most patients, but good semen from very few. Only one pregnancy has yet been achieved. The technique has diagnostic applications.

"Electroejaculation" is the word generally used to denote the obtaining of semen by electrical stimulation with electrodes in the rectum. The name is a little misleading, because the semen is rarely or never ejaculated in the strict sense; it trickles from the external urinary meatus without the help of contractions of striated muscles. The technique has been used in domestic animals since 1936. Most veterinary users have employed sinusoidal alternating current of frequencies from 15 to $100 \mathrm{~Hz}$, delivered through rigid rectal probes, a substantial fraction of whose surface was covered with electrodes. ${ }^{1}$

Published accounts of its application to $\operatorname{man}^{2-7}$ consider only its use for rendering paraplegic men fertile. Two pregnancies thus achieved have been reported, ${ }^{47}$ one of them ${ }^{7}$ yielding a live baby. Stimuli have been sinusoidal at frequencies from two ${ }^{3}$ to $90^{6} \mathrm{~Hz}$ or have consisted of trains of unidirectional pulses of duration one ${ }^{6}$ to $15^{6} \mathrm{~ms}$ and frequency five ${ }^{6}$ to $140^{5} \mathrm{~Hz}$, and they have been applied through probes similar to those used in veterinary practice. No writer, I believe, has discussed the rational choice of stimulus parameters or electrode sizes or positions, and I can find no substantial body of empirical observation on these matters in either the abundant veterinary literature or the scanty medical literature.

\section{Preliminary investigations}

Theory What is needed is to stimulate the right nerve fibres, and as few as possible of the wrong ones, with

Address for reprint requests: Professor GS Brindley, Institute of Psychiatry, De Crespigny Park, Denmark Hill London SE8 8AF.

Accepted 18 September 1980 the least possible risk of thermal and electrolytic damage to the rectal mucosa. To select a particular nerve or compact plexus it is advantageous to have a single circular cathode and a larger anode or group of anodes. The diameter of the cathode should be roughly equal to its least distance from the nerve or plexus; a greater diameter worsens the discrimination, and a smaller diameter causes the current density close to the electrode to be unnecessarily and perhaps harmfully high. These desiderata are roughly obvious from theory, and can be confirmed from experience in stimulating motor points and cutaneous nerves through the skin.

In attempting to stimulate from the rectum anatomically defined structures in the pelvis one would expect discrimination to be better with an electrode mounted on a glove-finger than with one mounted on a rigid probe, and probably the risk of doing mechanical damage is less with a glove-finger. To minimise electrolytic damage, one should ensure that no net direct current is passed (which some earlier workers have done), and also minimise the electrical charge transferred per cycle (which none of them have done). To minimise thermal damage, one should, amongst other things, minimise the electrical power consumed, and this has never before been attempted. For both these purposes, if the fibres that one is intending to stimulate are myelinated (and it will be argued below that they are), the stimulating pulses should be short. Charge per pulse at the threshold for a myelinated fibre falls with duration down to roughly $80 \mu \mathrm{s}$ and remains nearly constant below this. Energy per pulse at such a threshold falls with duration down to roughly $150 \mu \mathrm{s}$ and rises below this. Thus pulses of $100 \mu$ s duration will be not very far from minimising both charge and energy; at least they will be much better in both respects than the sinusoidal currents or 1 to $15 \mathrm{~ms}$ pulses used in previous published work.

Animal Experiments All experiments and surgical procedures on animals were done under deep pentobarbitone anaesthesia. In ten male baboons and four 
male rhesus monkeys, I explored what happened when sites accessible to a cathode of $4 \mathrm{~mm}$ diameter mounted on a glove-finger were stimulated electrically through the rectum. I was able to produce separately, on either side, the movements appropriate to the pudendal, sciatic, inferior gluteal, superior gluteal, obturator, or genitofemoral nerve. The femoral nerve could be stimulated, but usually not without also stimulating the genito-femoral. In all 14 animals, stimulation at sites giving obturator or genitofemoral effects gave full or nearly full erection, with threshold roughly two or three times that for somatic effects.

In two baboons a urethral catheter was passed and the bladder pressure measured. The region from which a rise in bladder pressure was obtained with lowest threshold was centred on the best site for stimulating the obturator nerve. All stimulation which increased the bladder pressure also caused some erection, but in the more caudal part of the effective region the erection was slight though the rise in bladder pressure was large $(40 \mathrm{mmHg}$ or more). Just rostral to the effective region was one from which erection could be provoked without any rise in bladder pressure.

In seven of the 10 baboons and three of the four rhesus monkeys semen was obtained as a result of the procedure, but it was often not clear which of several sites of stimulation had caused the emission. I therefore repeated the procedure in one of the baboons and one of the rhesus monkeys with the abdomen opened and the vas deferens of both sides surgically exposed in the spermatic cord and upper scrotum. In both animals, the site that gave contraction of the seminal vesicle and vas deferens with lowest threshold was just rostral to the ipsilateral obturator nerve point. The response fatigued if stimulation was repeated at 15 second intervals, but two minutes' rest sufficed for its recovery. The contraction produced from either obturator point was restricted to the ipsilateral seminal vesicle and vas deferens. Stimulation in the midline just rostral to the prostate caused contraction on both sides, but with threshold higher by a factor of 1.6 to $1 \cdot 8$. The contractions involved all the visible part of the vas deferens, that is from the upper border of the testis to about $2 \mathrm{~cm}$ below the pubic crest and from the lateral inguinal fossa to the bladder. The most easily visible manifestation of them was a shortening, so that undulations of the vas disappeared and it took as straight a course as possible between its points of attachment. No peristaltic waves were seen. The strength-duration relation for producing contraction of the left vas deferens by stimulating the left obturator point was measured in the baboon. The chronaxie was $0.6 \mathrm{~ms}$.

In four male baboons and three male rhesus monkeys I implanted electrodes on the hypogastric plexus immediately in front of the bifurcation of the aorta. In all animals, stimulation through the implanted electrodes caused shrinkage of the penis together with a contraction of the seminal vesicles and vasa deferentia very similar to that seen during electroejaculation. In one of the rhesus monkeys the strength- duration relation for producing such contraction was measured. The chronaxie was $0.4 \mathrm{~ms}$.

Experiments on myself In me, trains of $100 \mu$ s pulses passed through a $6 \mathrm{~mm}$ circular cathode mounted either on a glove-finger or on a rigid probe will stimulate both motor and sensory fibres of the pudendal nerves from the upper part of the anal canal without causing severe pain, though always with some pain. It is even possible to produce a maximal contraction of the muscles innervated by the pudendal nerve. ${ }^{8}$ From the posterolateral rectal wall, pressing backwards towards the sacral plexus of one side, I can produce ipsilateral toe flexion or plantarflexion of the foot, and tingling in various parts of the ipsilateral S2 and S3 dermatomes. These are always accompanied by diffuse deep pelvic pain, but the pain is not prohibitively unpleasant at threshold for the muscular and "cutaneous" effects. I cannot produce contraction of the gluteal or adductor muscles, or erection, ejaculation, micturition or the sensation of impending micturition. The strongest stimuli that pain allows me to tolerate are roughly $1 / 4$ (in voltage or current) of those needed for electroejaculation in patients.

\section{Methods}

EQUIPMENT FOR ELECTROEJACULATION IN MAN

Electrode mounts $\mathrm{My}$ first glove-finger electrode mounts were made from dental acrylic. The rigidity of this material hindered accurate palpation, but not as severely as one might expect. After about a year of using acrylic electrode mounts I changed to silicone rubber. Whatever the material of the electrode mount, it is made to extend beyond the tip of the finger by about $20 \mathrm{~mm}$, and the cathode, whose diameter is about $8 \mathrm{~mm}$, lies on the palmar surface of this extension. There are two anodes in parallel, each of area equal to that of the cathode or a little greater, on the dorsal surface centred 18 and $50 \mathrm{~mm}$ proximal to the cathode. Such electrode mounts are made by Mr C M Andrew of 43 Landcroft Road, London SE22, and can be bought from him.

Stimulator I assume that in man, as in the baboon and rhesus monkey, electroejaculation depends on the stimulation of myelinated fibres. I therefore adhere rigidly to $100 \mu \mathrm{s}$ as the duration of the stimulating pulses. Until May 1980 I always used 30 pulses per second, because I had found in 1977 that this was effective, and there seemed to be no reason to change it. Since May 1980 I have had reason to use lower frequencies, and have often done so. At first I used a general purpose electrophysiological stimulator, putting a capacitor in series with the output to prevent the passage of direct current. Now I use a compact $(19 \times 11 \times 8 \mathrm{~cm})$ battery-driven stimulator designed by (and purchasable from) Mr C M Andrew, giving the following stimulus parameters: pulse duration $100 \mu \mathrm{s}$; peak voltage of pulse up to $108 \mathrm{~V}$ (9 equally-spaced steps) into $1 \mathrm{M} \Omega$ load, up to $80 \mathrm{~V}$ into the usual load of $250 \Omega$; time-constant of sag of pulse $800 \mu \mathrm{s}$; peak current into $250 \Omega$ up to $316 \mathrm{~mA}$; nett current less 
than $0.1 \mu \mathrm{A}$; output impedance $60-90 \Omega$ (highest at highest voltage setting); time-constant of decay of return current between pulses $10 \mathrm{~ms}$; frequency of pulses 30,15 or 10 per second (switchable).

\section{PROCEDURE}

My usual practice is to have the patient supine with knees bent (though it is possible to use the left lateral, or even the prone position). It is useful to have a helper standing on the patient's left to hold the left leg. I stand on the right and put the electrode mount on the right index finger over a plastic or rubber glove. I put some aqueous jelly (KY jelly is suitable) on the tip of the electrode mount and over the electrodes, and insert the electrode mount into the anal canal until the cathode and distal anode and half of the proximal anode are within the canal. Then stimulation at 9 volts should cause contraction of the anal sphincter, and, with a little adjustment of the rotation and depth of the electrode mount, the left or right ischiocavernosus muscle. I next turn my hand so that its palm faces down and, pressing gently downward with the finger-tip, advance the electrode mount as far in as it goes easily with very gentle pressure. The cathode is now near the best places for stimulating the sacral plexus and its somatic branches. Using 36 to 54 volt pulses, I explore the posterior wall of the pelvis for sites giving flexion of the toes, plantarflexion at the ankles, visible contraction of the hamstrings, abduction of the thighs, visible contraction of the buttocks, external rotation at the hips, or palpable contraction of the obturator internus muscles. It is usually possible to obtain all of these, separately or in various combinations, on either side, and this may provide useful diagnostic information. But when the procedure is being used solely to obtain semen, it suffices to obtain any one of the somatic motor effects. If I get none at $54 \mathrm{~V}$ I try at $80 \mathrm{~V}$. If still none can be obtained, then either no anterior horn cells survive from the 5 th lumbar to the 2 nd sacral segment, or the stimulator is not working, or there is much gas in the rectum, preventing the anodes from making good contact. In the last case the gas can be expelled by pressing on the abdomen, pulling laterally with the finger to assist its release.

I next turn the palmar surface of the finger so that it faces directly to the patient's right, and advance the finger as far as possible, pushing hard. I then explore the right lateral wall of the pelvis for the obturator point, that is the site where 80 -volt stimulation causes powerful adduction of the right thigh. Stimulation here usually yields semen (if semen can be obtained at all) after from 5 to 20 seconds. If there is none in $40 \mathrm{sec}-$ onds I try the left obturator point. To reach the left obturator point it is sometimes necessary to transfer the electrode mount to the left hand and stand on the patient's left.

\section{Results}

In 256 attempts at electroejaculation on 89 men
(84 with spinal injuries and five others), I have obtained semen externally in $163(64 \cdot 1 \%)$, retrogradely in $44(17 \cdot 2 \%)$ and not at all in $49(19 \cdot 1 \%)$. But these figures are overweighted with men on whom I have had many (in one case 31 ) successes. Table 1 classifies the results on men with spinal injuries by patients rather than by attempts. "External success" means that on at least one occasion liquid containing spermatozoa (not necessarily motile) trickled from the meatus. On 11 of these 36 men only one attempt was made. On four of them two attempts were made, and both were externally successful. On 21 of them from three to thirty-three attempts were made, of which some (usually most) were externally successful, the remainder being either retrograde or unsuccessful.

"Retrograde success" means a patient from whom I have never obtained semen externally, but whose next urine passed after an attempt at electroejaculation has contained at least $5 \times 10^{6}$ spermatozoa. On six of these 14 men only one attempt was made. On five men two or more attempts were made, all retrogradely successful. On three men two attempts were made, one retrogradely successful and the other unsuccessful.

"Definite failure" means a patient in whom on one occasion (17 cases) or on three occasions (three cases), attempted electroejaculation has yielded no liquid at the meatus (15 cases) or liquid containing no spermatozoa (five cases), and the next urine passed has contained no spermatozoa (13 cases) or fewer than $5 \times 10^{6}$ spermatozoa (seven cases).

"External failure" means a patient from whom no semen was obtained externally, and who failed to provide a specimen of urine. All such patients were seen once only.

"Pain prevented" means a patient in whom, at the only attempt at electroejaculation, stimulation at less than the strength needed for success in other patients was intolerably painful.

Partly retrograde ejaculation Ten of the 36 men listed in table 1 as external successes also on occasion gave purely retrograde ejaculation. It would thus not be surprising if ejaculation was sometimes partly external but partly retrograde. Merely finding spermatozoa in the next urine passed after an externally successful electroejaculation is insufficient to prove such an occurrence; it is necessary to collect the urine in two lots, the first (of at least $20 \mathrm{ml}$ ) to wash out the urethra, and the second as a sample of real bladder contents. I have done this on three occasions (different patients) when I already suspected that ejaculation was partly retrograde, and on all three 
occasions found more spermatozoa in the bladder urine than in the external ejaculate.

Prevention by pain Every patient who could recognise pinprick in no lumbar or sacral dermatome could tolerate electroejaculation without anaesthesia. Every patient who could recognise pinprick in a sacral or L5 or L4 dermatome was unable to tolerate it. Patients who could recognise pinprick in an $\mathrm{L} 1$ to $\mathrm{L3}$ dermatome but not below were unpredictable.

General anaesthesia and neuromuscular block Table 2 summarises the ten patients on whom I have attempted electroejaculation under general anaesthesia, usually with neuromuscular block (succinylcholine). Six had spinal injuries or spina bifida, and in four of these the reason for using general anaesthesia was that an attempt at electroejaculation without anaesthesia had been prevented by pain. In the other two, the reason was that attempts without anaesthesia had been retrogradely successful. I then tried under general anaesthesia with neuromuscular block, and from one of the two patients obtained semen externally. A similar conversion from retrograde to external ejaculation was achieved in one of the two otherwise healthy men who had never ejaculated in the waking state. My first electroejaculation of him, done under general anaesthesia without muscle relaxant, was retrogradely successful. Five subsequent electroejaculations, all done with neuromuscular block, have yielded semen externally.

\section{SIDE-EFECTS OF ELECTROEJACULATION}

Contractions of striated muscles These are a valuable guide to the position of the stimulating cathode. Under general anaesthesia they agree with what would be expected from the stimulation of nearby $\alpha$ motor fibres. In unanaesthetised patients these direct motor effects are accompanied by reflex effects. Often the reflex effects are variable from time to time in the same patient, and they may occur after rather than during stimulation; but sometimes they are so repeatable and so immediately related to the stimulus that only their anatomical inappropriateness shows that they are not direct motor effects. The commonest such pseudo-direct response of striated muscle is contraction of the abdominal muscles on stimulation of branches of the sacral plexus; I have notes of its occurring in seven patients and think it occurred in a few others. Almost simultaneous contraction of the adductors of both sides in response to stimulation of the obturator nerve on one side has occurred in at least four patients. I

Table 1 Success and failure of electroejaculation in patients with spinal injuries

\begin{tabular}{|c|c|c|c|c|c|c|}
\hline $\begin{array}{l}\text { Highest clinically } \\
\text { damaged cord } \\
\text { segment }\end{array}$ & External success & Retrograde success & Definite failure & External failure & Pain prevented & Total \\
\hline C6 to T1 & $\begin{array}{l}13 \\
\text { (4 incomplete) }\end{array}$ & $\begin{array}{l}1 \\
\text { (incomplete) }\end{array}$ & $\stackrel{5}{(2 \text { incomplete })}$ & 3 & 0 & 22 \\
\hline $\mathrm{T} 2$ to $\mathrm{T} 12$ & $\begin{array}{l}21 \\
\text { (3 incomplete) }\end{array}$ & $\begin{array}{l}11 \\
\text { (1 incomplete) } \\
\text { (1 flaccid) }\end{array}$ & $\begin{array}{l}13 \\
(6 \text { flaccid) } \\
\text { (1 incomplete) }\end{array}$ & $\begin{array}{l}3 \\
\text { (2 flaccid) }\end{array}$ & $\begin{array}{l}2 \\
\text { (both incomplete) }\end{array}$ & 50 \\
\hline L1 or below & $\stackrel{2}{(1 \text { incomplete) }}$ & $\stackrel{2}{\text { (flaccid) }}$ & $\stackrel{2}{(1 \text { flaccid })}$ & $\begin{array}{l}1 \\
\text { (flaccid) }\end{array}$ & $\begin{array}{l}5 \\
(2 \text { incomplete }) \\
\text { (1 flaccid) }\end{array}$ & 12 \\
\hline Total & 36 & 14 & 20 & 7 & 7 & 84 \\
\hline
\end{tabular}

Table 2 Electroejaculation under general anaesthesia

\begin{tabular}{lll}
\hline External success & Retrograde success & Definite failure \\
\hline 1 complete L2 lesion & $\begin{array}{l}\text { 1 complete T5 lesion (patient with } \\
\text { transurethral resection of bladder neck) }\end{array}$ & 1 T12/L2 lesion (flaccid patient) \\
1 incomplete T12 lesion & & $\begin{array}{l}\text { i abdomino-perineal excision of rectum for } \\
\text { carcinoma (electrodes inserted through } \\
\text { colostomy) }\end{array}$ \\
$\begin{array}{ll}1 \text { complete T4 lesion } & 1 \text { diabetic non-ejaculator without other } \\
\text { evidence of neuropathy } & \end{array}$ \\
$\begin{array}{l}1 \text { lumbar spina bifida } \\
\text { (5 and } 6 \text { external successes respectively) }\end{array}$ & & \\
\hline
\end{tabular}

The five patients in table 2 who had spinal injuries are listed also in table 1. 
have never seen pseudo-direct contraction of the quadriceps, adductors or ilio-psoas in response to stimulation of the sacral plexus, or pseudo-direct contraction of the gluteal muscles, or of any muscle below the knee, to stimulation on the opposite side.

In six of the 146 externally successful electroejaculations without general anaesthesia, emission of semen has been accompanied by rhythmic contractions of the abdominal muscles. The temporal pattern of these contractions roughly resembled that of orgasmic pelvic floor contractions, ${ }^{9}$ but they lacked the progressive increase in interval that occurs at orgasm. On two of these six occasions the rhythmic contractions included the anal sphincter.

Rhythmic abdominal contractions (not including the anal sphincter) were seen in one of 47 unsuccessful and in one of 44 retrogradely successful electroejaculations.

After-effects on spasm Several patients have mentioned that for a few hours after electroejaculation their legs are less spastic than usual. Others, when directly questioned, have denied any such effect. No patient has reported increase in spasm. Micturition Stimulation that is intended to yield semen sometimes yields urine instead, or a mixture of urine and semen. Of the 15 men whom I have electroejaculated three or more times with external success (most of them six or more times), eight have never given semen mixed with urine, three have done so on a minority of occasions, and four on the majority of occasions. Of the 22 men whom I have electroejaculated once or twice with external success, three have given semen mixed with urine.

There are two means by which the release of urine with semen can sometimes be prevented. The first uses the anatomical separation of sympathetic and parasympathetic fibres that might be expected from anatomical textbooks, and was seen in the baboon experiments. Stimulation near the best site for stimulating the superior gluteal nerve of ten gives urine without semen. When the bladder has by this means been made emptier than the patient can get it by his own efforts, stimulation at or a little cranial to the best site for the obturator nerve may give pure semen. The second method uses the effect of pulse frequency. In the baboon ${ }^{10}$ and in human patients (Brindley, Polkey \& Rushton, unpublished), stimulation of preganglionic sacral parasympathetic fibres at 30 pulses/s gives very much stronger detrusor contractions than at 15 or fewer pulses/s. For electroejaculation, however, 15 pulses/s are almost as good as $30 / \mathrm{s}$ in the baboon. In man they are at least sometimes adequate, and yield pure semen where 30/s had yielded mixed semen and urine from the same patient.

Erection I have done some externally successful electroejaculations without causing any penile erection, and very many with only a slight erection. But there are men in whom seminal emission cannot, with my technique, be achieved without an accompanying full erection, and others in whom erection sometimes but not always occurs. Contraction of the dartos muscle A train of large pulses delivered to almost any site in the pelvis causes in nearly all patients a conspicuous contraction of the dartos after a delay of 3-5 seconds. This response is absent or very feeble under general anaesthesia, but I have seen it clearly and reproducibly present in a patient with a T8 lesion in whom there was no evidence (unless this dartos response be such) of any functioning cord or surviving anterior horn cells below the level of the lesion. In two otherwise similar patients with T6 and $\mathrm{T} 7$ lesions the dartos response was absent.

Rise in blood pressure In patients with lesions at $\mathrm{T} 5$ or below I do not usually record the blood pressure. No such patient has reported headache during the procedure. In patients with lesions above $\mathrm{T} 5$, electroejaculation nearly always raises the blood pressure. I formerly used an automatic sphygmomanometer (Dynamap 845). Now I use an ordinary sphygmomanometer repeatedly, or feel the pulse, inflate a sphygmomanometer cuff to $200 \mathrm{mmHg}$, and not whether the pulse reappears. If the systolic pressure reaches $200 \mathrm{mmHg}$ or if the patient reports headache I stop stimulating. The blood pressure then always falls within a few tens of seconds, and I often resume stimulation (if semen has not yet been obtained) within a minute.

\section{CORRELATES OF FAILURE}

In five of the 20 patients classified as definite failures, electroejaculation yielded liquid at the external urinary meatus that looked like semen but contained no spermatozoa. The volumes were $3.5,2.0,0.3,0.2$ and $0.1 \mathrm{ml}$. In another three patients, no liquid appeared at the meatus, but acid phosphatase and fructose were substantially more abundant in the next urine passed after electroejaculation than in urine passed before it. Another patient was of eunuchoid appearance and had very small testes. It seems likely that in all or most of these nine patients the electrical stimulation had its proper effect on the prostate, seminal vesicles, and vasa deferentia, but the 
patients were azoospermic from disease or injury of the upper genital tract.

Six patients with whom I definitely failed had no evidence of any surviving anterior horn cells below T6, T7, T8, T9, L1 and L2. In the last two of these, damage extended on one side up to T12. Two patients, both with complete T11 lesions, had intact muscles of the L5 and sacral myotomes, but severe wasting of the quadriceps, adductors, and iliopsoas. It seems likely that in all or most of these patients the sympathetic fibres that the procedure should stimulate were lost.

There remain two patients where definite failure is entirely unexplained. Both had cervical lesions, and only one attempt at electroejaculation was made. Their urines were not examined for fructose, acid phosphatase or other genital-tract markers (eg arginine or $\gamma$-glutamyl transferase).

THE INFLUENCE OF SURGICAL OPERATIONS ON THE BLADDER NECK AND URETHRA

Twelve patients have had transurethral resection of the bladder neck; of these, three have also had transurethral external sphincterotomy. Five of these patients were external successes, and five retrograde successes. Two were "definite failures", in both cases with evidence that retrograde emission of azoospermic semen had occurred. Thus transurethral resection of the bladder neck certainly does not make external emission impossible, though it probably increases the proportion of retrograde to external emissions. Only one patient has had external sphincterotomy and no resection of the bladder neck. He is the one patient who has become a father. Of 33 attempts at electroejaculation on him, 31 have been externally successful. The other two (both early in the series) were definite failures.

\section{ELECTROEJACULATION IMMEDIATELY AFTER}

REMOVING A FOLEY CATHETER

This has been done 34 times on 13 patients. Twenty-one attempts (seven different patients) were externally successful, seven attempts (on four of the preceding patients) were retrogradely successful, and six attempts (six different patients) were definite failures.

QUALITY OF SEMEN IN MEN WITH SPINAL INJURIES I nearly always measure the specimen, and do counts of motile spermatozoa and all spermatozoa, within 40 minutes. Paraplegic semen is usually liquid; only for about one specimen in 10 is there need to wait for liquefaction.
The volume can be from $0.2 \mathrm{ml}$ to $10.5 \mathrm{ml}$ (the latter without evident contamination by urine). The average is about $2 \mathrm{ml}$. The number of spermatozoa per unit volume can be normal, but is more often low (less than 40 million/ml). Two patients have repeatedly given specimens with counts exceeding 500 million $/ \mathrm{ml}$, and six other patients have at least once had counts exceeding 200 million $/ \mathrm{ml}$. The fraction of spermatozoa that swim is almost always low. Among 166 external ejaculates examined, the highest motilities were $78 \%$ (T10 complete lesion of one year's duration), $48 \%$ and $33 \%$ (T5 complete lesion of 17 years' duration, injured at age 19 and first electroejaculated at age 36 ), $41 \%$ (T5 complete lesion of $1 \frac{1}{2}$ years' duration), $34 \%$ ( $\mathrm{T} 7$ complete lesion of seven years' duration), and $26 \%$ (C7 complete lesion of two years' duration). All the other 161 specimens had motilities under $26 \%$. In the 44 retrograde ejaculates (which by definition contained at least five million spermatozoa), motilities were zero in 32, and between $1 \%$ and $20 \%$ in 12 .

Fourteen wives of men with spinal injuries have been inseminated with the husband's semen, all of them more than once. Only one pregnancy has been achieved. Paternity was verified by examination (by Prof B E Dodd of the London Hospital) of 17 blood antigens, not including HLA. The child is healthy, walked at 11 months, and could say six distinguishable words at 14 months.

\section{DOMESTIC ELECTROEJACULATION}

The wives of 12 paraplegic men were asked whether they wished to learn to electroejaculate their husbands. Ten wished to and two did not. All the 10 who wished to learn have now learned, and are using the technique successfully at home. One of these wives is a physician, one a nurse, and one a physiotherapist. The other seven had no relevant previous knowledge or experience.

\section{Discussion}

SAFETY

Local heating The calculated power dissipation at the cathode during stimulation at $30 / \mathrm{s}$ at the highest voltage setting is at most 0.11 watt $\mathrm{cm}^{-2}$. In two recent electroejaculations done at these settings the temperature rise was monitored by a bead thermistor mounted on the centre of the cathode. The temperature rises in 30 seconds of stimulation were 0.25 and $0.30^{\circ} \mathrm{C}$. There is no kind of single or double failure in the stimulator that could increase the power dissipation by more 
than a factor of five; such an increase could occur only if there were three simultaneous faults, one of them being the insertion of the wrong kind of fuse in the fuse-holder.

Electrolysis The net direct current passed by the blocking capacitors during stimulation at $30 / \mathrm{s}$ at the highest voltage-setting is less than $10^{-7} \mathrm{~A}$, that is at least 100 times too low to cause electrolytic damage. In five patients I examined the rectal mucosa with a sigmoidoscope a few minutes after electroejaculation. The sites of stimulation were indistinguishable from the surrounding mucosa. Blood-staining of the next faeces passed has been reported to me after only two of 256 electroejaculations on 89 patients. There are two blocking capacitors in series, each rated at $160 \mathrm{~V}$, and the potential across them cannnot exceed $96 \mathrm{~V}$. It is thus very unlikely that either will fail, and much more unlikely that both will.

Ventricular fibrillation The current density at the heart produced by the pelvic stimulation used for electroejaculation can be calculated if we assume the human body to be a uniform conductor. Though this assumption is inaccurate, it is unlikely to overestimate or underestimate the current density by more than a factor of 2 or 3. The current density in a uniform conductor at distance $D$ from a dipole of length $d$ carrying current $I$, where $D$ is substantially greater than $d$, is $\mathrm{dI} / 2 \pi \mathrm{D}^{3}$ along the axis of the dipole and less at any other orientation. In the present case the length of the dipole is at most $3 \mathrm{~cm}$, the distance from the dipole to the heart at least $20 \mathrm{~cm}$, and the current during a pulse at most $316 \mathrm{~mA}$, giving a peak current density at the nearest part of the heart of $19 \mu \mathrm{Acm}^{-2}$, and an rms current density of $1.0 \mu \mathrm{Acm}^{-2}$ at 30 pulses per second and 0.5 $\mu \mathrm{Acm}^{-2}$ at 15 pulses per second. The official safe limit for $50 \mathrm{~Hz}$ alternating current is $50 \mu \mathrm{Acm}^{-2}$ rms. In pigs of weight $15-25 \mathrm{Kg}, 300 \mathrm{~mA}$ peak current from head to knee in trains of $3.7 \mathrm{~ms}$ pulses was required to produce ventricular fibrillation. ${ }^{11}$ Assuming $600 \mathrm{~cm}^{2}$ (probably a substantial overestimate) for the non-lung non-fat crosssectional area of the chests of such pigs, the peak current density at the heart would be $500 \mu \mathrm{Acm}^{-2}$. Even on these criteria the currents used for electroejaculation should be safe by a factor of at least 25 , and the $100 \mu$ s pulses used should be less (and perhaps very much less) effective in causing ventricular fibrillation than $3.7 \mathrm{~ms}$ pulses of the same peak amplitude. To further confirm that the stimulus parameters used have a large margin of safety for the heart, in one anaesthetised baboon the $100 \mu$ s pulse stimulator was connected between electrodes of area $5 \mathrm{~cm}^{-2}$ in the mouth and in the rectum and switched on for a minute at maximum amplitude (EMF $108 \mathrm{~V}$ ) and 30 pulses per second. This caused very powerful tonic contraction of the trunk muscles which probably involved every motor unit in the whole trunk. Breathing ceased, but the heart continued to beat in regular sinus rhythm throughout the minute of stimulation. Breathing returned within a few seconds of the end of stimulation. This baboon weighed $12 \mathrm{Kg}$ and the non-lung cross-sectional area of its chest was about $350 \mathrm{~cm}^{2}$. The peak current in each pulse was $520 \mathrm{~mA}$, so the peak current density through the heart was about $1.5 \mathrm{~mA} \mathrm{~cm}^{-2}$.

Elevation of blood pressure When electroejaculation is being done on patients with high lesions the blood pressure must be measured, and stimulation stopped if it rises too high or if the patient reports severe headache. What pressure should be regarded as too high, and whether mild headache should be taken as a ground for stopping, are matters on which I can give no authoritative opinion. But it seems reasonable to suggest that if the systolic pressure does not rise above 200 $\mathrm{mmHg}$ and the headache is neither distressing to the patient nor more severe than he has already experienced in previous episodes of autonomic dysreflexia, no excessive risk has been taken.

\section{WHAT IS BEING STIMULATED TO CAUSE EMISSION} OF SEMEN

Electroejaculation works well under general anaesthesia, and is then very unlikely to depend bon a reflex. In unanaesthetised patients, the emission of semen was in all but 2 of 146 externally successful trials unaccompained by rhythmic pelvic floor contractions such as occur in normal orgasm. It is thus unlikely that success in the unanaesthetised ordinarily depends on triggering a reflex response of the cord; if it did, this reflex would have to be very different from the orgasmic reflex of the intact cord. What of the two occasions when rhythmic pelvic floor contractions did accompany seminal emission? One of these was the only electroejaculation of a patient, but the other was one of five electroejaculations of a patient who emitted semen externally on all five oscasions, with rhythmic abdominal contractions including the anal sphincter once, rhythmic abdominal contractions without anal sphincter contractions twice, irregular abdominal contractions once, and no obvious skeletal muscular activity once. It seems likely that even here the seminal emission depends on electrical stimulation of efferent fibres; rhythmic reflex activity can occur 
simultaneously with it, but is probably a separate and independent phenomenon.

The sites that are best for causing seminal emission agree fairly well with those that one would expect, from known anatomy, to contain substantial numbers of sympathetic fibres to the genital tract, and they are remote from the sensory fibres that serve the known receptive field for reflex ejaculation. In me, and in the patients with incomplete or low lesions, the sensations produced by stimulating at these sites are nongenital, wholly unpleasant, and not conducive to sexual arousal. These facts provide further reasons for doubting whether the seminal emission produced by my technique is ever reflex.

The chronaxies found for contraction of the vas deferens in the rhesus monkey and baboon are very much lower than those found for unmyelinated fibres, ${ }^{12}$ and are typical of myelinated fibres. This leads immediately to the conclusion that the relevant sympathetic fibres are myelinated (and hence presumably preganglionic) at the sites stimulated, that is in front of the bifurcation of the aorta and between the rectum and the obturator nerve.

It would be very difficult to measure the chronaxie for electroejaculation in men, and $I$ have not attempted it. But the relatively low thresholds found for $100 \mu$ s pulses make it probable that myelinated fibres are being stimulated. The largest unmyelinated fibres have electrical thresholds only twice those of small myelinated fibres for long pulses, but at least 20 times for short pulses, ${ }^{12}$ so that it is difficult to believe that the present stimuli can have excited more than a very few favourably placed unmyelinated fibres.

THE SEGMENTAL ORIGIN OF THE NERVE FIBRES INVOLVED IN SEMINAL EMISSION

Table 3 shows all patients with complete traumatic lesions at T6 or below who gave external success, good retrograde success $\left(>20 \times 10^{6}\right.$ spermatozoa) or definite failure without evidence for azoospermic emission. The more stringent criterion of retrograde success is to reduce the risk of including cases where spermatozoa were released spontaneously into the urine of expressed mechanically by the electroejaculation procedure. Two patients are thus excluded; they have T11 and T12 lesions. Four "definite failures" in the sense of table 1 are excluded, two (both T6 lesions) because they gave azoospermic external ejaculates and two (T11 and T12) because of high fructose and acid phosphatase in the urine collected after electroejaculation.

From cases 1-18 it seems that no single segment (unless just possibly T8 or T11) is the source of all the fibres involved in seminal emission. Since cord lesions are rarely if ever as short as one segment, we may even tentatively infer that no pair of consecutive segments is the source of all the fibres. Case 17 is very informative. He twice gave good retrograde emission, despite complete absence of responses to electrical stimulation of motor nerves in all segments from T12 downward on the left and from L1 downward on the right. He had no trace of erection, reflexly or in the electroejaculation procedure or (he says) psychically. For him we can say almost certainly that the

Table 3 Patients with complete lesions at T6 or below who gave external success, good retrograde success, or definite failure not attributable to azoospermia

\begin{tabular}{|c|c|c|c|c|c|}
\hline \multicolumn{2}{|c|}{ External success } & \multicolumn{2}{|c|}{ Good retrograde success } & \multicolumn{2}{|c|}{ Definite failure } \\
\hline 1 & T6 & & T7 (resection of bladder neck) & 19 & T6, flaccid \\
\hline 2 & T6 & & T12 & 20 & T7, flaccid \\
\hline 3 & T6 & & T12 & 21 & T8, flaccid \\
\hline 4 & T6 left, T7 right & & T12 left, L1 right, flaccid & 22 & T9, incomplete, flaccid \\
\hline 5 & $\mathrm{T7}$ & & T12 left, L2 right & 23 & T11, partly wasted muscles down to L4 \\
\hline 6 & T7 right, T8 left & & & 24 & $\begin{array}{l}\text { T11, completely wasted muscles down to } \\
\text { L4 }\end{array}$ \\
\hline 7 & T9 & & & 25 & T12 right, L1 left, flaccid \\
\hline 8 & T9 & & & 26 & $\begin{array}{l}\text { T12 right, L2 left, flaccid (general } \\
\text { anaesthetic) }\end{array}$ \\
\hline 9 & T9, partly wasted muscles down to $\mathbf{L} 3$ & & & & \\
\hline 10 & T9 & & & & \\
\hline 11 & T10 & & & & \\
\hline 12 & T12 & & & & \\
\hline 13 & L2 (general anaesthetic) & & & & \\
\hline
\end{tabular}


lumbar and sacral segments of the cord are unnecessary for seminal emission. The only slight reservation is that loss of all $\alpha$ anterior horn cells does not absolutely prove loss of all intermediate horn cells in the same segment.

Cases 25 and 26 seem to conflict with case 17, but both were failures on a single occasion without chemical analysis of the urine for genital-tract markers.

Cases 23 and 24 suggest that loss of all the sympathetic outflow from T11 downwards probably prevents success in elestroejaculation. Case 9 (in whom I have had many external successes) is not in sharp conflict, because of the incompleteness of his wasting.

Cases 19-22 all showed no trace of somatic motor responses in the electroejaculation procedure. Even the dartos response was absent in cases 19, 20 and 22, though it was present (to my surprise) in case 21 . Case 22 was incomplete only in having slightly preserved tactile sensation.

The predominance of low lesions among the retrograde successes suggests that a low lesion may interrupt the sympathetic fibres to the bladder neck without destroying all those to the vasa deferentia and seminal vesicles.

\section{IMPROVING THE QUALITY OF SEMEN}

The figure of merit that $I$ use is the estimated number of motile spermatozoa in the whole ejaculate, that is the product of volume, count per $\mathrm{ml}$, and fraction motile. On this index the best paraplegic ejaculate that I have seen does not match average normal semen, and most paraplegic ejaculates are very bad. They are also usually abnormal in being liquid when emitted.

Possible reasons for the poor quality include non-drainage, chronic infection, and raised scrotal temperature. I have some evidence that all these three are contributory, and that remedying them is practicable and beneficial; but this work has a long way to go before it will be fit to publish, except for the firm finding that deep scrotal temperatures are on the average higher in paraplegics in wheelchairs than in age-matched and similarly clothed seated normal men. ${ }^{13}$

\section{THE TREATMENT OF MEN WHO EJACULATE}

\section{RETROGRADELY}

Spermatozoa may remain motile for three hours or more in urine provided that it is not too acid ( $\mathrm{pH}$ less than about 6.2) or too dilute (total solutes less than about $150 \mathrm{mosm} / \mathrm{Kg}$ ). It thus seems possible that retrograde ejaculates might be used. after centrifugation, for inseminating. Sodium bi- carbonate $5 \mathrm{~g}$, given by mouth one or two hours before, ensures appropriate $\mathrm{pH}$ and concentration. However, centrifugation may not be harmless, and even the best urine is unlikely to be a good environment for spermatozoa.

In two men who previously ejaculated retrogradely I have obtained semen externally by electroejaculating under general anaesthesia with neuromuscular block. It seems likely that this technique will be widely applicable. The same end, that is relaxation of the striated muscles that close the urethra, could doubtless be achieved by pudendal block or sacral epidural block.

\section{RANGE OF APPLICATION}

Diagnostic use The electroejaculation procedure provides a quick and simple means of examining, in a patient of either sex with a complete transection of the spinal cord, which muscles of the lower limbs retain a motor innervation. It is applicable during the period of spinal shock, provided that three or four days have elapsed since injury, so that motor fibres whose perikarya have been destroyed have lost their excitability. The same end can be achieved by stimulation of motor points through the skin, but the electroejaculation procedure is much quicker.

In theory, the electroejaculation procedure should distinguish between a deafferented and a totally denervated bladder. These behave alike in ordinary cystometry. At present the distinction makes little or no difference to treatment, but this may not remain true in the future.

Fertility of men with injury or disease affecting the spinal cord or cauda equina This is the "established" (though as yet only slightly successful) field of application. It will probably be the most important, if means can be found for improving the quality of the semen.

Fertility of otherwise healthy men with ejaculatory failure Only two such patients have been referred to me. With both I have been regularly successful, and the counts and motilities are within normal limits. Though no pregnancy has yet been achieved, there is ground for optimism.

Injuries and disease affecting peripheral nerve fibres in the pelvis It seems likely that when these conditions cause ejaculatory failure they usually do so by destroying the efferent pathway, so electroejaculation will fail. However, there may be a few cases where it will succeed.

\section{References}

1 Ball L. Electroejaculation. In: Klemm WR, ed. Applied Electronics for Veterinary Medicine and 
Animal Physiology. Springfield, CC Thomas, 1976; 394-441.

2 Horne HW, Paull DP, Munro D. Fertility studies in human male with traumatic injuries of the spinal cord and cauda equina. New Engl J Med 1948; 239:959-61.

3 Bensman A, Kottke FJ. Induced emission of sperm utilizing electrical stimulation of the seminal vesicles and vas deferens. Arch Phys Med Rehab 1966; 47:436-43.

4 Thomas RJS, McLeish G, McDonald IA. Eectroejaculation of the paraplegic male followed by pregnancy. M J Aust 1975; 2:798-9.

5 David A, Ohry A, Rozin R. Spinal cord injuries: male infertility aspects. Paraplegia 1977; 15:11-14.

6 Res P, Plevnik S, Suhel P. Electroejaculation in spinal cord injured patients. International Continence Society, 7th Annual Meeting 1977; Paper 6:21-22.

7 Francois N, Maury M, Jouannet D, David G, Vacant J. Electroejaculation of a complete para- plegic followed by pregnancy. Paraplegia 1978; 16:248-51.

8 Brindley GS, Rushton DN, Craggs MD. The pressure exerted by the external sphincter of the urethra when its motor nerve fibres are stimulated electrically. Br J Urol 1974; 46:453-62.

9 Masters WH, Johnson, VE. Human sexual response. Boston: Little, Brown \& Co., 1966:185.

10 Brindley GS. An implant to empty the bladder or close the urethra. J Neurol, Neurosurg Psychiatry 1977; 40:358-69.

11 Jacobsen J. Die Gefährdung durch phasenangeschnittene und gleichgerichtete elektrische Ströme. Hannover: Technische Universität (Dr. Ing. thesis) 1973.

12 Blair EA, Erlanger, J. A comparison of the characteristics of axons through their individual electrical responses. Am J Physiol 1933; 106: 524-64.

13 Brindley GS. Deep scrotal temperature and the effect on it of clothing, air temperature, activity, posture, and paraplegia. $\mathrm{Br} J$ Urol (in Press). 